\title{
Google's search data and its Application in finance
}

\author{
Bodo Herzog $1,2,3$ \\ ${ }^{1}$ ESB Business School, Reutlingen, Germany \\ ${ }^{2}$ Institute of Finance and Economics (IFE), Germany \\ ${ }^{3}$ Reutlingen Research Institute, Reutlingen University, Germany
}

\section{Email address:}

Bodo.Herzog@Reutlingen-University.DE

\section{To cite this article:}

Bodo Herzog. Google's Search Data and its Application in Finance. International Journal of Economics, Finance, and Management Sciences. Vol. 2, No. 1, 2014, pp. 1-7. doi: 10.11648/j.ijefm.20140201.11

\begin{abstract}
This paper examines the relationship of asset price determination via Google data. To capture this relation, I create a model and estimate several time series' regressions. I use weekly data from 2004 to 2010 from 30 international banks. To my knowledge this is the first study which differentiates between Google's search volume and Google's search clicks. I show that asset prices are positively related to the rate of change in Google's search volume, trading volume and the level of Google search clicks. Secondly, I demonstrate that the absolute level of Google's search volume and Google's search clicks behave differently regarding the asset price dynamics. Google's search volume, which measures long-run searches, is negatively related while Google's search clicks have a positive relationship to asset prices. Hence, Google's data offer new insights on both measuring attention and pricing financial assets.
\end{abstract}

Keywords: Search Data, Asset Price, Asset Bubbles, Google Measures

\section{Introduction}

Economists have been studying the determination of asset prices for many years. In fact, the Nobel Prize in economics to Eugene F. Fama, Lars P. Hansen, and Robert J. Shiller in 2013 demonstrates this fact sufficiently. A critical element in all studies is the measurement of attention during the pricing process [1,2]. The literature assumes that economic agents can gather the relevant information and then use it to make proper investment decisions. However, recent empirical and theoretical work by Cohen and Lou [3] and Duffie [4], and the knowledge of the theory of bounded rationality, emphasize that information processing is more complex and takes time [5]. Consequently, the investigation of how attention affects and determines asset prices is difficult in an environment of asymmetric information and bounded rationality. Until today, there is almost no direct data for the measurement of investors' attention.

In a recent paper Da, Engelberg and Gao [6] suggest a direct measure for attention apart from the existing proxies such as trading volume [7], news and headlines or extreme stock returns [8]: Google search data. Following this idea, I evaluate the quality of Google's search data and trading volume as a measurement for asset price determination. In contrast to the paper by [6], I focus on banks in general and cross-country effects in particular. Moreover, my study is the first to differentiate between Google's search volume and Google search clicks. In light of these facts, this paper contributes in several ways to the pre-embryonic empirical literature about the usage of Google data.

Obviously, Google data gain importance because more and more financial trading processes are done electronically and via algorithmic high frequency traders. The impact of these processes is illustrated by the recent flash crash on May 6th 2010, when high frequency trades caused the Dow Jones Industrial Average to plump by seven hundred points in just a few minutes. In this paper, I analyze the effects of attention and determination of asset prices. In doing so, I have to limit the attention to three leading banking institutions in 11 different OECD countries. The comparable size and limited number of financial institutions is necessary for studying cross-country variation. The limitation to three banks per country may produce a selection bias, but the selected banks cover a considerable market share in each country. Moreover, only the three biggest banks provide sufficient Google search per day which is necessary for the empirical study.

I demonstrate that the use of Google search data is an important step towards the identification of information based stock price fundamentals. A few years ago, Choi and Varian [9] proposed that search data has the potential to 
forecast a variety of important economic variables. This statement is expected to be strengthened in a so-called mobile age with increasing online access. The usage of Google is adequate because it is currently dominating the market of search engines. However, this source consists of two segments: (1) Google Trends which is later on referred to as Google search volume and (2) Google Insights which is now called Google search clicks.

Data from Google Trends contain the search volume for different search expressions and measures the number of searches by its time-series' average. Google calls this index a relative number index which measures how many times a certain term is searched compared to its long-run average. It is important to recognize that the numbers are not absolute search traffic but scaled to the average search which is one. To give an example, let's take a look at Google search data that is rated 1.9. This can be interpreted as a search traffic that is 1.9 times higher than the long-run average over the period from 2004 to 2010. However, Google Insights data offer a measurement of instant Google search clicks. Therefore, I use both measures and examine the difference of attention in the long-run by Google search volume and in the short-run by Google search clicks that is an instant measure. The data range is from 2004 to 2010 because Google data is only available from 2004 onwards. Moreover since 2012, Google merged both measures and does not further differentiate between search volume and search clicks.

The contributions in my paper are threefold: (1) I build a new theoretical model of asset pricing which includes the idea of attention; (2) I estimate and compare the Google data and asset prices; finally (3) I evaluate the role of Google data during asset bubbles. In contrast to [6], I use two different sources of Google's search data and thus reveal an even more comprehensive picture.

The remainder of the paper is organized as follows: Section 2 describes the model and the data in detail. The results are discussed in section 3. Finally, section 4 concludes the paper.

\section{Model}

The theoretical foundation of asset pricing is based on the Lucas asset-pricing model [10]. For this analysis however, I incorporate two new elements into the standard model: (1) I explicitly model the dynamics of the dividend process via a stochastic differential equation and (2) I consider search behavior on either good or bad news on the dividend process. The standard Lucas model is extremely useful when studying empirical issues such as asset price determination $[11,12,13]$. My extended theoretical model contributes to the finance literature because it is one step towards a theoretical understanding of Google search and asset price determination.

Suppose there are $n$ risky assets in the economy. They generate a stochastic return equal to $\delta_{i t}$ per period. The assets are the only source of income and $p_{i t}$ is the price of asset $i$ in period $t$. Hence, $p_{t}$ and $\delta_{t}$ are both vectors of prices and dividends at time $t$. The economy consists of identical and infinitely living individuals which maximize the expected utility as stated below

$$
\mathbb{E}\left[\sum_{t=0}^{\infty}(\theta)^{-t} U\left(c_{t}\right) \mid 0\right]
$$

In any period, the individual receives dividends on the quantity $x_{i t}$ of each asset that he or she holds between period $t$ and $t+1$. Hence, if $x_{t}$ is an $n$ by 1 vector, the budget constraint gets

$$
c_{t}+p_{t}^{\prime} x_{t}=\left(p_{t}+\delta_{t}\right)^{\prime} x_{t-1}
$$

The right-hand side of eq. (2) illustrates the household income at time $t-1$, including dividends. The left-hand side is equal to consumption plus the new value of assets at time $t$. The first-order conditions of this optimization problem are

$$
p_{i t} U^{\prime}\left(c_{t}\right)=(1+\theta)^{-1} \mathbb{E}\left[U^{\prime}\left(c_{t+1}\right)\left(p_{i t+1}+\delta_{i t+1}\right) \mid t\right], i=1, \ldots, n \text {.(3) }
$$

In equilibrium, the quantities of each asset demand must be equal to the exogenous supply. Without loss of generality, suppose there is only one unit of each asset,i.e. $x_{i t}=1$ for all $i$ and $t$. Consequently, consumption must be equal to output, which is the sum of dividends according to the budget constraint (eq. 2): $c_{t}=\sum \delta_{i t}$. In addition, equation (3) is a recursive relation which determines the price of assets as a function of exogenous variables. The solution of equation (3) is straightforward ${ }^{1}$ and leads to:

$$
p_{i t}=\mathbb{E}\left[\sum_{j=0}^{\infty}(1+\theta)^{-j}\left(\frac{U^{\prime}\left(c_{t+j}\right)}{U^{\prime}\left(c_{t}\right)}\right) \delta_{i t+j} \mid t\right] .
$$

According to this solution, the asset price is equal to the expected discounted present value ${ }^{2}$ of dividends. To derive testable results it is necessary to make further assumptions about the utility function and the distribution of dividends. First, individuals are assumed to be risk neutral so that the first derivative of the utility function $U^{\prime}\left(c_{t}\right)$ stays constant. Second, the dividend process is assumed to follow a stochastic differential equation, such as

$$
\frac{d\left(\delta_{t}\right)}{\delta_{t}}=\left(f_{t}+a_{t}\right) d t+\sigma d W_{t}
$$

Where $f_{t}$ represents the stock fundamentals, $a_{t}$ is the measurement of attention, and $\sigma$ is the volatility. Finally, $d W_{t}$ is a Wiener process. The attention variable $a_{t}$ is modeled as follows

$$
a_{t}=\left\{\begin{array}{l}
S V_{t} \text { for good news } \\
-S V_{t} \text { for bad news }
\end{array} \text { with } S V_{t}>0 \quad \forall t\right.
$$

The variable $S V_{t}$ stands for search volume and is measured by (Google). I use the assumption that both good and bad news generate higher search traffic. However, I suppose that news change the attention and finally the asset

\footnotetext{
${ }^{1}$ We use the standard assumption of no bubbles or no-Ponzi-schemes.

2 The discount rate is the marginal rate of substitution between consumption at time $\mathrm{t}+\mathrm{j}$ and consumption at time $\mathrm{t}$.
} 
price to buy in case of good news and to sell in case of bad news. Consequently, good news increases and bad news decreases the future stream of dividends. Furthermore, I implicitly assume that financial statements and news announcements result in a higher search activity. Using these assumptions I resolve and rewrite equation (4) as

$$
p_{i t}=\mathbb{E}\left[\sum_{j=0}^{\infty}(1+\theta)^{-j}\left(\int\left(f_{t+j}+a_{j+t}\right) \delta_{i t+j} d(t+j)+\int \sigma \delta_{i t+j} d W_{t+j}\right) \mid t\right]
$$

Equation (7) enables me to analyze how the asset price behaves over time given the different determinants. In short, the price is equal to the discounted present value of expected dividends discounted at a constant rate, which is the subjective discount rate of individuals. Asset prices are also affected by movements in expected dividends and consist of two parts: (a) the drift term $\left(f_{t+j}+a_{j+t}\right) \delta_{i t+j}$ and (b) the diffusion term $\sigma \delta_{i t+j}$. Higher dividends as a result of more search traffic due to good or bad news add attention and should affect the stock price. But higher dividends also mean higher consumption and thus lower marginal utility - other factors remaining unchanged. Therefore, dividends are valued less when attention and consumption are high.

Next, let me talk about my data. Google data are publicly available and obtained from Google.com. From 2004 onwards, the search index is available on a weekly basis. I focus on the attention of banking stocks in the past seven years which allows the identification of cross-country differences. Consequently, I collect a data set across the G7 member states. Additional to the G7 countries, I include the same number of financial institutions from Switzerland, Spain and China. Therefore, in total, I have 11 countries.
The reason I include Spain in our sample is that, thanks to their regulated financial market, Spanish banks were not much affected by the financial crisis of 2007 to 2009 but later by the European sovereign debt crisis. Due to the fact that the Chinese banks were not listed on a stock exchange before September 30, 2007, the data is limited in this case. A complete list of all relevant banks and descriptive statistics is in the appendix (Table 1A, 2A).

In addition to trading volume and asset prices, I consider the overall performance of the stock market for each country. All in all, by combining the time-series' dimension with a maximal value of $\mathrm{t}=324$ (number of weeks) and the cross-sectional dimension of $\mathrm{n}=30$, I create panel data.

Similar to an econometric study by [14], I left out other company fundamentals and the state of the economy. However, due to multi-collinearity caused by the relatively high correlation between the stock price and these variables, I make sure to calculate standard errors adjusted to autocorrelation and heterogeneity.

\section{Estimation Results}

I first examine the relationship between the change in Google search volume (GSV) and other proxies, including the level, the stock index, the asset price and the stock return. The results, which are reported in Table 1, contain different models with cross-section fixed-effects and weekly fixed-effects. The standard errors are clustered. The tests of fixed-effects are reported in Table 3A of the appendix.

Table 1.The Change in GSV asa Measurement of Attention

\begin{tabular}{lcccc}
\hline Variables & $\mathbf{( 1 )}$ & $\mathbf{( 2 )}$ & $\mathbf{( 3 )}$ & $\mathbf{( 4 )}$ \\
\hline Intercept & $0.768^{* * *}(0.126)$ & $0.052(0.033)$ & $0.198(0.266)$ & $0.197(0.265)$ \\
$\log ($ Google Search Volume $)$ & $0.136^{* * *}(0.010)$ & $0.115^{* * *}(0.009)$ & $0.162^{* * *}(0.011)$ & $0.162^{* * *}(0.011)$ \\
$\log ($ Index $)$ & $-0.116^{* * *}(0.016)$ & $-0.010^{* * *}(0.003)$ & $-0.041(0.030)$ & $-0.040(0.030)$ \\
$\log$ (Price) & $0.052^{* * *}(0.007)$ & $0.003^{* * *}(0.001)$ & $0.031^{* * *}(0.008)$ & $0.030^{* * *}(0.008)$ \\
$\log$ (Return) & $-0.012 * *(0.002)$ & $-0.007 * * *(0.002)$ & $-0.008^{* * *}(0.002)$ & $-0.008^{* * *}(0.002)$ \\
Change of Trading Volume & & & & $0.0001^{* * *}(0.0001)$ \\
Cross-section Fixed Effects & YES & NO & YES & YES \\
Period Fixed Effects & NO & YES & YES & YES \\
Observations & 3857 & 3857 & 3857 & 3857 \\
Adjusted R ${ }^{2}$ & 0.052 & 0.224 & 0.238 & 0.166 \\
S.E. of regression & 0.145 & 0.137 & 0.136 & 0.136 \\
F-statistic & $6.324 * * *$ & $3.269 * * *$ & $3.209^{* * *}$ & $3.239^{* * *}$ \\
Durbin-Watson stat & 2.142 & 2.183 & 2.150 & 2.152 \\
\hline
\end{tabular}

Dependent variable: Change of Google Search Volume. The standard errors clustered by banks are in parentheses. *, ** and *** represents significance at the $10 \%, 5 \%$ and $1 \%$ level.

Comparing the four regressions, I discover that the econometric models are robust and almost all coefficients are significant. I confirm that the change in Google search volume (GSV) is positively related to both the level of Google search and the asset price. This suggests that high asset prices result in more attention and increased Google search. Moreover, this is first evidence of a price-momentum effect, just known from theoretical literature in finance $[14,15]$. A high level of Google search is related to higher growth of search which points to a certain overreaction of our attention measure.

The available Google data provide also insight about asset bubbles, i.e. the relationship of price and fundamentals. Both the stock index and the returns have negative signs and partly significant coefficients. Hence, an increase in the rate of return slows down the Google searches. Consequently, the attention gets less in a banking stock if the return is high which is during an unforeseen upturn or downturn. Thus, 
studying Google search data provides new signals of underor overheating in prices and thus the development of bubbles. Moreover, the change in trading volume and Google search volume is statistically positively related.

Next, I estimate the change in Google's search volume as well as the first- and second-order lag variable. This procedure helps to identify possible time-series effects of my Google measure. The results reported in Table 2 show that Google search volume and trading volume are robust across all econometric models.

Table 2.The Change in GSV, Panel Estimates

\begin{tabular}{|c|c|c|c|}
\hline Variables & (1) & (2) & (3) \\
\hline Intercept & $-0.001(0.001)$ & $-0.001(0.003)$ & $-0.001(0.003)$ \\
\hline $\log ($ Google Search Volume $)$ & $1.312 * * *(0.005)$ & $1.133 * * *(0.005)$ & $1.137 * * *(0.005)$ \\
\hline $\log ($ Google Search Volume, -1$)$ & $-1.311 * * *(0.009)$ & $-1.133 * * *(0.005)$ & $-1.127 * * *(0.006)$ \\
\hline $\log ($ Google Search Volume, -2$)$ & & - & $-0.011 * * *(0.005)$ \\
\hline $\log ($ Trading Volume $)$ & & $0.001 *(0.001)$ & $0.002 * *(0.001)$ \\
\hline $\log ($ Trading Volume, -1$)$ & & $-0.001 *(0.001)$ & $-0.002 * *(0.001)$ \\
\hline Period Fixed Effects & YES & YES & YES \\
\hline Observations & 8921 & 8455 & 8426 \\
\hline Adjusted $\mathrm{R}^{2}$ & 0.731 & 0.868 & 0.868 \\
\hline S.E. of regression & 0.089 & 0.048 & 0.048 \\
\hline F-statistic & $75.76 * * *$ & $172.3 * * *$ & $172.0 * * *$ \\
\hline Durbin-Watson stat & 2.544 & 2.574 & 2.575 \\
\hline
\end{tabular}

Dependent variable: Change of Google Search Volume. The standard errors clustered by banks are in parentheses. *,** and *** represents significance at the $10 \%, 5 \%$ and $1 \%$ level.

Table 3.Determinants of Stock Price

\begin{tabular}{|c|c|c|c|}
\hline Variables & (1) & (2) & (3) \\
\hline Intercept & $5.771 * * *(0.315)$ & $1.893(1.614)$ & $1.627(1.819)$ \\
\hline $\log$ (Google Search Volume) (by Google Trends) & $-0.176 * * *(0.011)$ & $-0.015 * *(0.006)$ & $-0.015^{* *}(0.006)$ \\
\hline $\log$ (Google Search Clicks) (by Google Insights) & $0.215 *(0.119)$ & $0.001 * *(0.001)$ & $0.001 *(0.001)$ \\
\hline $\log ($ Trading Volume $)$ & $-0.152 * * *(0.005)$ & $-0.013 * * *(0.001)$ & $-0.013 * * *(0.001)$ \\
\hline $\operatorname{AR}(1)$ & & $0.999 * * *(0.001)$ & $0.942 * * *(0.010)$ \\
\hline $\operatorname{AR}(2)$ & & & $0.057 * * *(0.010)$ \\
\hline Cross-section Fixed Effects & YES & - & - \\
\hline Period Fixed Effects & YES & - & - \\
\hline Observations & 8361 & 8326 & 8293 \\
\hline Adjusted $\mathrm{R}^{2}$ & 0.977 & 0.998 & 0.998 \\
\hline S.E. of regression & 0.269 & 0.065 & 0.065 \\
\hline F-statistic & $1.026 * * *$ & $156129 * * *$ & $1246976 * * *$ \\
\hline Durbin-Watson stat & 0.119 & 2.119 & 2.014 \\
\hline
\end{tabular}

Dependent variable: Log of Stock Price. The standard errors clustered by banks are in parentheses. $*$, ** and *** represents significance at the $10 \%, 5 \%$ and $1 \%$ level.

As expected for a leading variable the first-order lag has a negative sign for GSV and trading volume. Subsequently I estimate a model that explains the stock price dynamics as a natural logarithm in relation to the other variables, in particular the trading volume. The estimation results are again robust and statistically significant (Table 3). Nevertheless, I cannot ignore the observation that asset prices can be explained by Google search. Interestingly, there is a significant positive relation between the asset price and instant Google search clicks, i.e. search clicks can be related to its rise in prices. As soon as the Google search volume (long-run search) is above the average and simultaneously the Google search clicks are further growing, the asset price moves into a bubble or follows herd behavior. This effect is demonstrated by the statistically significant negative impact on stock prices via the variable of Google search volume. In other words, high attention measured by instant Google clicks has a positive impact on the price.

In line with my extended pricing model in section 2 , high search clicks affect instantaneously the parameter $a_{t}$ and thus search clicks are positively related to the stock price. Hence, Google search clicks - measured by Google Insights - might be a better measurement of attention than the usage of Google search volume based on the long-run search average.

In addition, and as expected in the existing econometric literature, stock prices and trading volume are significantly in a negative relationship with each other. This means that if trading volume increases by a unit the stock price is affected negatively due to the estimated coefficient of -0.01 to -0.15 . Although the coefficients of trading volume are small, I cannot deny this link. This finding is robust for all models. The cause for this negative relationship could be the fact that 
trading volume is a leading variable and measures price contagion. If all investors purchase or sell a stock today, it will cause a high trading volume automatically. Therefore, trading volume signals busy or congested markets with declining profit margins. Accordingly, a stock becomes less attractive in the heat of a boom or the wake of a crisis.

All results support the hypothesis that Google search data are a relevant indicator for investors' decisions. In regression model (2) and (3) I include an autoregressive term to capture the time series property. The first- and second-order autoregressive terms are both statistically significant. I also established a simple vector autoregressive model (VAR) and analyzed the corresponding impulse responding functions. Overall, the VAR model confirms the findings. The impulse response functions illustrate the positive price reaction after a standard shock by Google search volume (Table 4A, Figure 4A - Appendix).

In general, all estimations show that the empirical results are on line with expectations in literature. Since Google's statistics have an impact on stock price and trading volume, bankers and investors may want to consider this variable in future in more detail. There is no doubt, that Google is a relevant indicator for asset price determination as well as nowcasting. Any news released by the public relations department could raise investors' attention and, later, be measured by Google's search.

\section{Conclusion}

Throughout this paper, I have made several contributions to a new field of economic research: economic application of Google's search data. I built an asset pricing model which includes the idea of Google as a variable of attention. By

using Google, I am able to evaluate several new relationships and determinants of asset prices. To my knowledge, this paper is the first which compares both Google sources - Insights and Trends - and therefore is a unique contribution to the economics literature.

The usage of both Google measures allows us to disentangle the impact on short-run price trends and long-run fundamentals. This way I find evidence to the theoretical idea of a price momentum effect which, until now, has been an unproven theoretical proposition. Additionally, I reaffirm that attention, measured by Google, has a positive effect on prices.

To sum it up, according to the paper, Google statistics are a useful source. It is obvious that more research needs to be done on the predictive power of Google data. Although this paper provides a first evaluation, there is room for further research. I suggest an extension of the model to more macroeconomic fundamentals, analyst forecasts, economic sectors, and a rigorous evaluation of the forecasting and nowcasting power.

\section{Acknowledgements}

Special thanks to Katja Hengstermann, Verena Fischer and Garrit Winkler for editing the paper. In addition, I thank two anonymous referees. Finally, I am very grateful to Scott Marshall for inviting me to Portland State University at the School of Business Administration as visiting research professor in fall 2012 - 2013. I am responsible for all remaining errors.

\section{Appendix}

Table 1A.Data Overview - List of Banks according to Countries

\begin{tabular}{|c|c|c|}
\hline Country & Name of Bank & Time-series of Financial Data \\
\hline \multirow{3}{*}{ USA } & JP MORGAN CHASE \& CO. & March 1990 - March 2010 \\
\hline & WELLS FARGO \& CO. & March 1990 - March 2010 \\
\hline & BANK OF AMERICA & March 1990 - March 2010 \\
\hline \multirow{3}{*}{ Japan } & MITSUBISHI UFJ FINL. GP. & April 2001 - March 2010 \\
\hline & MIZUHO FINL. GP. & September 2000 - March 2010 \\
\hline & SUMITOMO MITSUI FINL. GP. & December 2002 - March 2010 \\
\hline \multirow{3}{*}{ Germany } & DEUTSCHE BANK & January 1999 - March 2010 \\
\hline & COMMERZBANK & April 2000 - March 2010 \\
\hline & DEUTSCHE POSTBANK & June 2004 - March 2010 \\
\hline \multirow{3}{*}{ UK } & HSBC HDG. & July 1992 - March 2010 \\
\hline & BARCLAYS & April 1990 - March 2010 \\
\hline & ROYAL BANK OF SCTL. GP: & April 19990 - March2010 \\
\hline \multirow{3}{*}{ France } & BNP PARIBAS & October 1993 - March 2010 \\
\hline & CREDIT AGRICOLE & January 2002 - March 2010 \\
\hline & SOCIETE GENERALE & June 1991 - March 2010 \\
\hline \multirow{3}{*}{ Italy } & UNICREDIT & April 1993 - March 2010 \\
\hline & INTESA SANPAOLO & July 1993 - March 2010 \\
\hline & BANCA MONTE DEI PASCHI & June 1999 - March 2010 \\
\hline \multirow{3}{*}{ Canada } & ROYAL BANK CANADA & April 1990 - March 2010 \\
\hline & TORONTO-DOMINION BANK & March 1990 - March 2010 \\
\hline & BANK OF NOVA SCOTIA & March 1990 - March 2010 \\
\hline Spain & BANCO SANTANDER & March 1990 - March 2010 \\
\hline
\end{tabular}




\begin{tabular}{cll}
\hline Country & Name of Bank & \multicolumn{1}{c}{ Time-series of Financial Data } \\
\hline \multirow{5}{*}{ China } & BBV. ARGENTARIA & April 1990 - March 2010 \\
& BANCO POPULAR ESPANOL & March 1990 - March 2010 \\
& INDUSTRIAL \& COML. BANK OF CHINA & October 2006 - March 2010 \\
& CHINA CONSTRUCTION BANK & September 2007 - March 2010 \\
\multirow{3}{*}{ Switzerland } & BANK OF CHINA & Juli 2006 - March 2010 \\
& CREDIT SUISSE GROUP & April 1990 - March 2010 \\
& UBS & March 2000 - March 2010 \\
\hline
\end{tabular}

Table 2A.Descriptive Statistics

\begin{tabular}{cccccc}
\hline & Price & Return & Index & Google Search Volume (GSV) & Google Insights Search Volume (GISV) \\
Mean & 489.080 & 0.000341 & 8515 & 1.047 & 16.293 \\
Median & 45.465 & 0.000000 & 6852 & 1.010 & 16.400 \\
Maximum & 13800.00 & 0.648000 & 40775 & 8.100 & 31.930 \\
Minimum & 0 & -0.789091 & 458.13 & 0.000 & 1.000 \\
Std. Dev. & 1679 & 0.063332 & 5750 & 0.453 & 8.767 \\
Skewness & 5.358 & -0.026439 & 2.089 & 1.832 & 0.008 \\
Kurtosis & 32.858 & 17.780 & 10.014 & 19.380 & 1.814 \\
Observations & 7844 & 7844 & 7844 & 7844 & 7844 \\
\hline
\end{tabular}

Table 3A.Test of Fixed-Effects

\begin{tabular}{|c|c|c|c|}
\hline Effect Tests & Statistic & d.f. & Prob. \\
\hline Cross-section F & 2.209 & $-29,3514$ & 0.0002 \\
\hline Cross-section Chi-square & 6.969 & 29 & 0.0000 \\
\hline Period F & 2.779 & $-309,3514$ & 0.0000 \\
\hline Period Chi-square & 843.308 & 309 & 0.0000 \\
\hline Cross-Section/Period F & 2.833 & $-338,3514$ & 0.0000 \\
\hline Cross-Section/Period Chi-square & 929.579 & 338 & 0.0000 \\
\hline
\end{tabular}

Note: Test cross-section and period fixed effects

Table 4A. VAR Model with Two Time Lags

\begin{tabular}{|c|c|c|c|c|}
\hline & LOGGSV & LOGI & LOGP & LOGR \\
\hline \multirow{3}{*}{ LOGGSV(-1) } & 0.651758 & 0.009294 & 0.022211 & 0.565821 \\
\hline & $(0.03145)$ & $(0.00539)$ & $(0.00953)$ & $(0.32919)$ \\
\hline & [20.7217] & [1.72426] & [2.33102] & [1.71885] \\
\hline \multirow{3}{*}{ LOGGSV(-2) } & 0.284155 & -0.002365 & 0.002462 & 0.199280 \\
\hline & $(0.03153)$ & $(0.00540)$ & $(0.00955)$ & $(0.32994)$ \\
\hline & [9.01362] & {$[-0.43781]$} & {$[0.25780]$} & [0.60399] \\
\hline \multirow{3}{*}{ LOGI(-1) } & 0.241725 & 0.985536 & -0.070869 & 0.727461 \\
\hline & $(0.18828)$ & $(0.03227)$ & $(0.05704)$ & $(-197.052)$ \\
\hline & [1.28387] & {$[30.5440]$} & [-1.24248] & [0.36917] \\
\hline \multirow{3}{*}{ LOGI(-2) } & -0.237467 & 0.013311 & 0.068535 & -0.777628 \\
\hline & $(0.18793)$ & $(0.03221)$ & $(0.05693)$ & $(-196.688)$ \\
\hline & [-1.26359] & {$[0.41330]$} & [1.20379] & {$[-0.39536]$} \\
\hline \multirow{3}{*}{ LOGP(-1) } & 0.044190 & 0.086800 & 1.432 .518 & 6.955 .889 \\
\hline & $(0.13704)$ & $(0.02349)$ & $(0.04152)$ & $(-143.430)$ \\
\hline & {$[-0.32245]$} & [3.69582] & [34.5042] & [4.84967] \\
\hline \multirow{3}{*}{ LOGP(-2) } & 0.040823 & -0.088107 & -0.432054 & -6.948 .909 \\
\hline & $(0.13710)$ & $(0.02349)$ & $(0.04153)$ & $(-143.484)$ \\
\hline & [0.29777] & {$[-3.75008]$} & [-10.4027] & [-4.84298] \\
\hline \multirow{3}{*}{ LOGR(-1) } & 0.002565 & -0.002005 & -0.003733 & -0.038709 \\
\hline & $(0.00429)$ & $(0.00074)$ & $(0.00130)$ & $(0.04492)$ \\
\hline & {$[0.59753]$} & {$[-2.72608]$} & {$[-2.87062]$} & {$[-0.86171]$} \\
\hline \multirow{2}{*}{ LOGR(-2) } & -0.000110 & $-1.40 \mathrm{E}-05$ & 0.002182 & 0.057313 \\
\hline & $(0.00304)$ & $(0.00052)$ & $(0.00092)$ & $(0.03179)$ \\
\hline
\end{tabular}




\begin{tabular}{lcccc}
\hline & LOGGSV & LOGI & LOGP & LOGR \\
& {$[-0.03606]$} & {$[-0.02694]$} & {$[2.37127]$} & {$[1.80280]$} \\
C & -0.020652 & 0.017417 & 0.031359 & -3.713 .076 \\
& $(0.05155)$ & $(0.00883)$ & $(0.01562)$ & $(0.53952)$ \\
Observations & {$[-0.40063]$} & {$[1.97147]$} & {$[2.00805]$} & {$[-6.88221]$} \\
R-squared & 908 & 908 & 908 & 908 \\
Adj. R-squared & 0.901847 & 0.999331 & 0.999658 & 0.130897 \\
S.E. equation & 0.900973 & 0.999325 & 0.999654 & 0.123163 \\
F-statistic & 0.100986 & 0.017307 & 0.030594 & 1.056 .922 \\
Akaike AIC & 1.032 .516 & 167747.8 & 328003.4 & 1.692 .492 \\
Schwarz SC & -1.737 .800 & -5.265 .606 & -4.126 .189 & 2.958 .461 \\
& -1.690 .111 & -5.217 .918 & -4.078 .500 & 3.006 .150 \\
\hline
\end{tabular}

Standard errors in ( ) \& t-statistics in [ ]
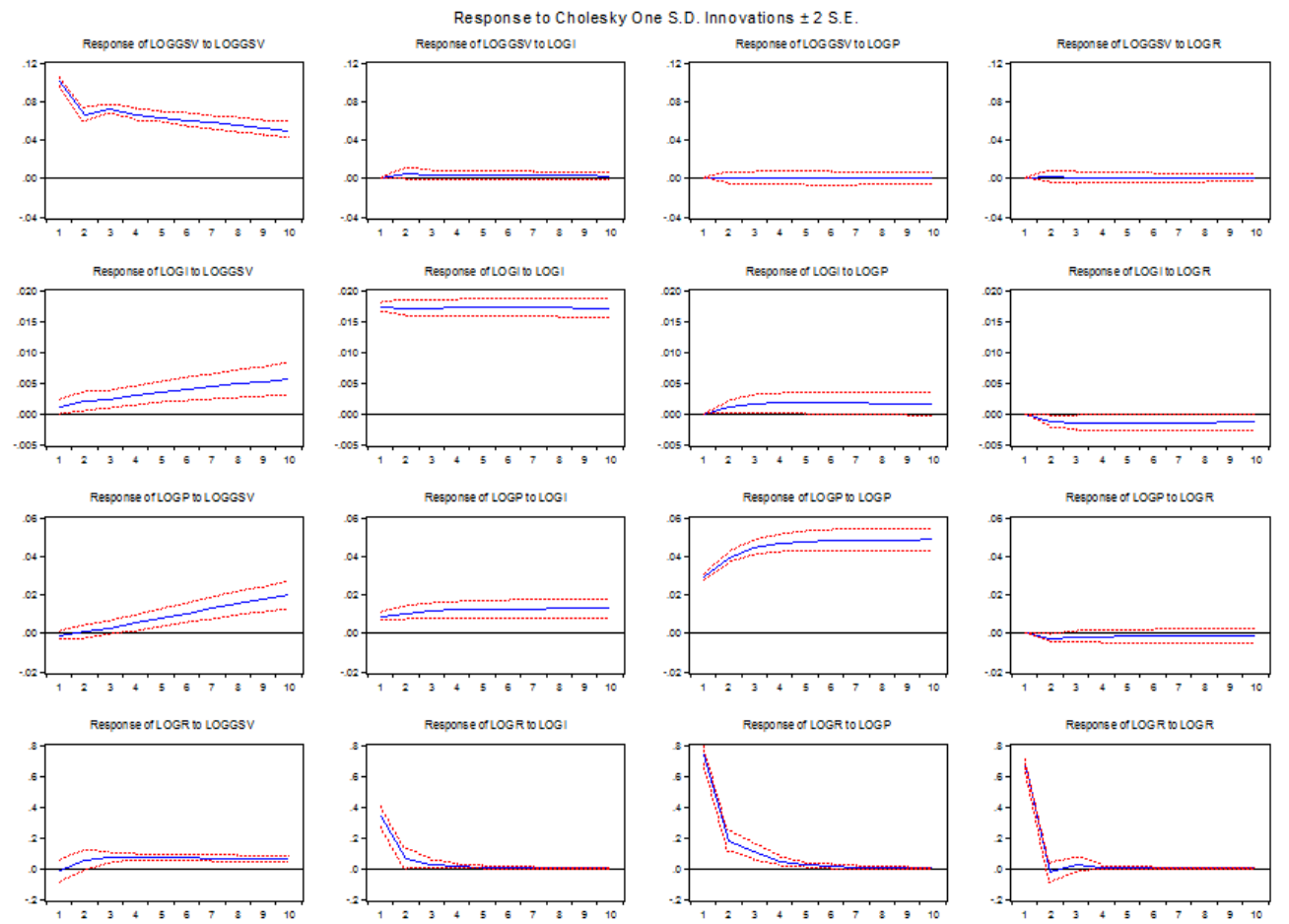

Figure 4A.Impulse Response Functions

\section{References}

[1] S. J. Grossmann and J.E. Stiglizt, "On the Impossibility of Informationally Efficient Markets," in American Economic Review, vol. 70, issue 3,1980, pp. 393-408.

[2] F. Allen, "The market for information and the origin of financial intermediation," in Journal of Financial Intermediation, vol. 1, issue 1, 1990, pp. 3-30.

[3] L. Cohen and D. Lou, "Complicated Firm," SSRN working paper, AFA 2011 Denver Meetings Paper, no. 1570869, October 2010.

[4] D. Duffie, "Presidential Address: Asset Price Dynamics with Slow-Moving Capital," in Journal of Finance, vol. 65, No. 4, 2010, pp. 1237-1267.

[5] D. Kahneman, "Attention and Effort," Prentice-Hall,1973.

[6] Z. Da, J. Engelberg and P. Gao, "In Search of Attention," in Journal of Finance, vol.66, No. 5, 2011, pp. 1461-1499.

[7] B.M. Barber and T. Odeau, "All That Glitters: The Effect of Attention and News on the Buying Behavior of Individual and Institutional Investors," in Review of Financial Studies, vol. 21(2), 2008, pp. 785-818.

[8] X. Li, R.S. Mahani and V. Sandhya, "Does Investor Attention Affect Stock Prices?," SSRN Working Paper, no. 1748851, March 2011.

[9] H. Choi and H. Varian, "Predicting the Present with Google Trends," Working Paper, www.google.com/googleblogs/pdfs/google_predicting_the_ present.pdf (14.03.2010, 09:37), 2009.

[10] R.E. Lucas, "Asset Prices in an Exchange Economy," in Econometrica, vol. 46, issue 6,1978, pp. 1426-1445. 